\title{
Pregnancy in uterus didelphys delivered by caesarean delivery: case report
}

\author{
Sneha S. Rao, Anitha GS*, Chandralekha P.
}

Department of Obstetrics and Gynaecology, ESIPGIMSR, Bangalore, Karnataka, India

Received: 26 April 2016

Accepted: 02 June 2016

\section{*Correspondence:}

Dr. Anitha GS,

E-mail: aninaik85@gmail.com

Copyright: () the author(s), publisher and licensee Medip Academy. This is an open-access article distributed under the terms of the Creative Commons Attribution Non-Commercial License, which permits unrestricted non-commercial use, distribution, and reproduction in any medium, provided the original work is properly cited.

\section{ABSTRACT}

Uterus didelphys represents a uterine malformation where the uterus is present as paired organ. There is presence of double uterine bodies with two separate cervices and often a double or septate vagina. Women with congenital malformations of uterus usually have higher incidence of complications during pregnancy and delivery. We report the case in our institute of a pregnancy in the left sided body of a didelphys uterus delivered by caesarean section.

Keywords: Uterine didelphys, Caesarean delivery, Mullerian duct

\section{INTRODUCTION}

Mullerian duct anomalies are congenital anomalies of the female genital tract arising from abnormal embryological development of the mullerian ducts. These abnormalities can include failure of development, fusion, canalization, or reabsorption, which normally occurs between 6 and 22 weeks in utero. Most sources estimate an incidence of these abnormalities to be 0.5 to $5.0 \%$ in the general population. ${ }^{1-4}$

Septate uterus is the commonest uterine anomaly with a mean incidence of $\sim 35 \%$ followed by bicornuate uterus $(\sim 25 \%)$ and arcuate uterus $(\sim 20 \%))^{4}$ A didelphys uterus, also known as a "double uterus," is one of the least common amongst MDAs. Duplication of the uterus results from lack of fusion of paramesonephric ducts in a local area or throughout their normal line of fusion. In uterus didelphys, individual horns are fully developed, normal in size with two cervices present. Each uterus has one fallopian tube. Some patients are asymptomatic while some patients suffer with primary infertility. In some patients, normal pregnancy can occur but obstetrical complications such as spontaneous abortion, still birth, preterm birth, malpresentation are frequent. ${ }^{5}$
Unicornuate and didelphys uterus have term delivery rates of $\sim 45 \%$, and the pregnancy outcome of patients with untreated bicornuate and septate uterus is also poor with term delivery rates of only $\sim 40 \%$. $^{4}$ Arcuate uterus is associated with a slightly better but still impaired pregnancy outcome with term delivery rates of $\sim 65 \%{ }^{4}$.

This report discusses a case of didelphys uterus that successfully conceived, carried her pregnancy to term, and delivered by caesarean delivery without any significant complications.

\section{CASE REPORT}

A 21 Years primigravida married for one year presented at 39 weeks of gestation with breech presentation to our labour room with complaint of labour pains. She had regular antenatal check-up's in a private clinic and was diagnosed to be having persistent breech presentation and was advised to undergo caesarean section in view of primigravida with persistent breech in labour. This was her first visit to our institute. 


\section{On general examination}

Patient is not anemic, pulse rate 78/minutes, BP 110/80 $\mathrm{mm}$ of $\mathrm{Hg}$ in left arm supine position. CVS and RSnormal.

\section{Per abdomen examination}

Uterus 39 weeks of gestational age, breech presentation, left sacro anterior, fetal heart rate- $140 \mathrm{bpm}$, uterus contractions are 3 in $10 \mathrm{~min}$ and each contraction lasting for $10-15$ second.

\section{On per vaginal examination}

Longitudinal vaginal septum present, two cervices felt. Left side cervix $80 \%$ effaced, $1.0 \mathrm{~cm}$ dilated. Right side cervix is unaffected, os closed. The fetal heart tracing was category one, showing a fetal heart rate of 150 at baseline, moderate variability, with accelerations and no decelerations. She had an ultrasound scan report done on the same day showing term breech presentation. Scan had not mentioned uterus didelphys. Case was posted for caesarean section in view of breech presentation with vaginal septum. Under spinal anaesthesia, abdomen opened by pfannensteil incision.

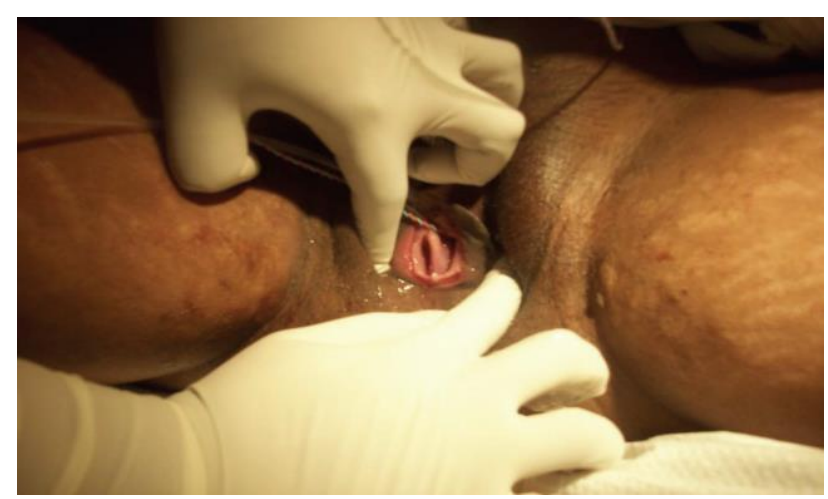

Figure 1: Non-communicable vaginal septum.

\section{Per operative findings}

Lower segment caesarean section was done. Baby presented as flexed breech and was delivered by breech extraction. An alive male baby of weight $2.5 \mathrm{~kg}$ with APGAR 8-10 was delivered. After delivery of the placenta, when uterus was exteriorized, another nongravid uterus was found on right side. It was diagnosed to be a case of uterus didelphys. Fetus was delivered from the left uterus. Each uterus had one fallopian tube and ovary. Both ovaries and tubes appeared to be healthy. Both uteri had separate cervices opening into separate vaginas. Bilateral kidneys were palpated and were normal.

Her postoperative recovery was uneventful. Dressing was done on $3^{\text {rd }}$ post-operative day. Skin stitches were removed on $6^{\text {th }}$ postoperative day and she was discharged on $7^{\text {th }}$ post-operative day.

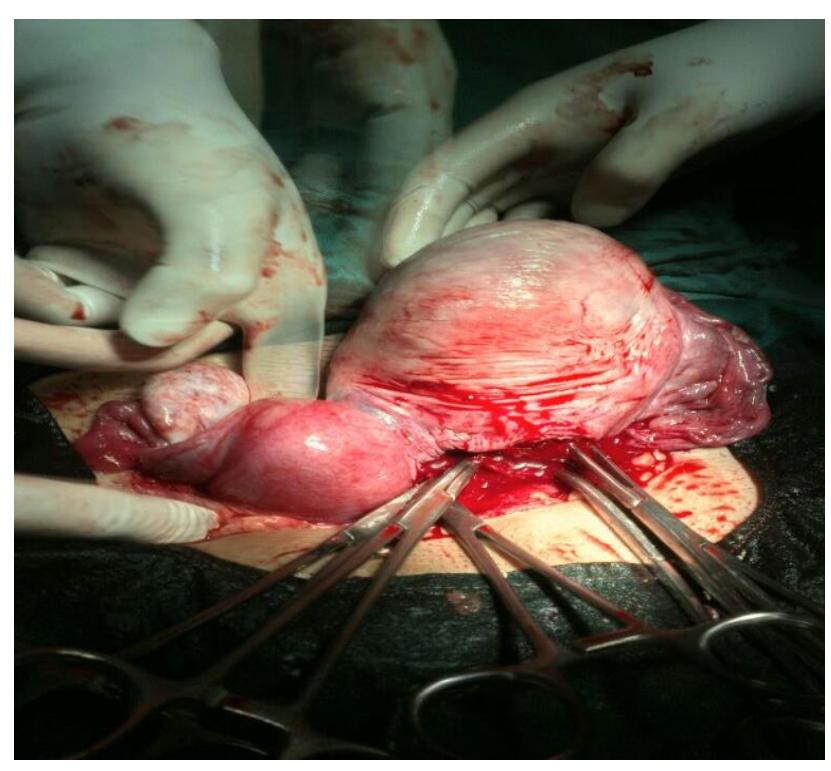

Figure 2: Intraoperative image of didelphys with gravid left horn.

\section{DISCUSSION}

Mullerian anomalies prevalence is exactly unknown. But recent study shows it is 0.1 to $10 \%$. Incidence of singleton pregnancy in uterine didelphys is 1 in 3000, incidence of twin gestations is 1 in 5 million, and incidence of triplets in uterine didelphys is 1 in 25 million. ${ }^{6}$

\section{Embryology}

Failure of the fusion of two paramesonephric ducts.

- Complete non fusion results in uterine didelphys

- Partial fusion of mullerian ducts results in bicornuate and septate uterus.

\section{Classification}

The most recent and widely used classification systems for the different types of Mullerian duct abnormalities were created by Buttram Jr. and Gibbons and the American fertility society. ${ }^{7,8}$

When classifying these anomalies solely based on abnormal development, four major types are apparent.

- Complete or partial failure of Mullerian duct development (agenesis; unicornuate uterus without a rudimentary horn)

- Failure of ducts to canalize (unicornuate uterus with a rudimentary horn without proper cavities)

- Incomplete fusion of Mullerian ducts (bicornuate or didelphys uterus) 
- Incomplete reabsorption of uterine septum (septate or arcuate uterus). ${ }^{4}$

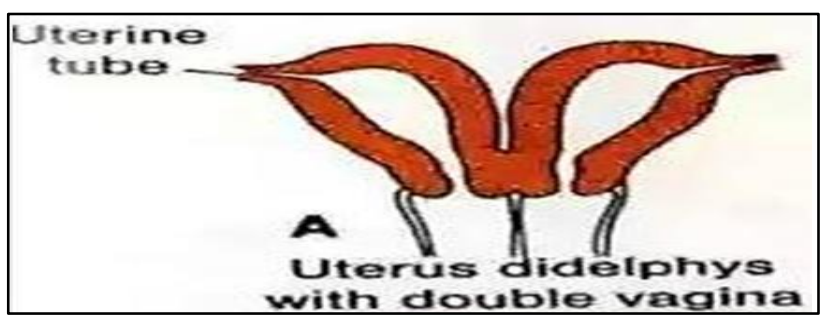

Figure 3: Graphical representation of uterine didelphys.

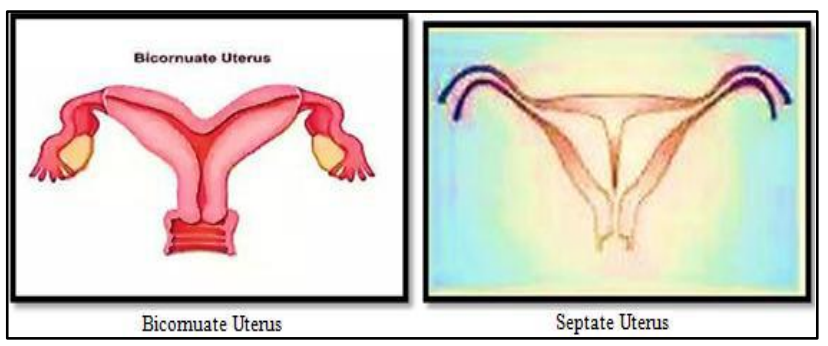

Figure 4: Graphical representation of bicornuate and septate uterus.

Most women with a didelphys uterus are asymptomatic, but may present with dyspareunia or dysmenorrhea in the presence of a thick, sometimes obstructing, vaginal septum. This obstructing vaginal septum can lead to hematocolpos/hematometrocolpos and thus present as chronic abdominal pain as well. Rarely, genital neoplasms and endometriosis are reported in association with cases of didelphys uterus. ${ }^{9}$

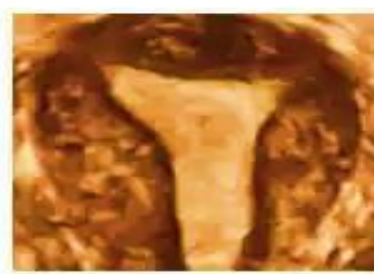

Normal uterus

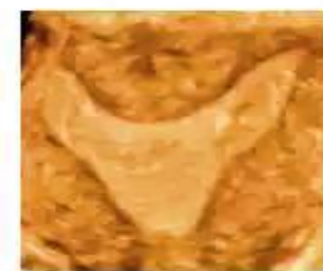

Heart shaped (arcuate) uterus
Frank breech is most frequent abnormal presentation in uterine didelphys. Management in patients with a double uterus may need special attention during pregnancy, as premature birth and malpresentations are common. Caesarean section was performed in $82 \%$ of patients with uterine didelphys. Other complications of pregnancy are cervical incompetence, $\mathrm{PPH}$, uterine rupture. ${ }^{10}$ As far as mode of delivery in patients with uterus didelphys, opinion is divided into normal vaginal delivery or elective cesarean section. Vaginal delivery has been accomplished merely by excision of vaginal septum. Because of high incidence of abnormal presentations and cervical incompetence, most of the people prefer cesarean section. ${ }^{11}$

Further, because the Mullerian ducts develop often in association with Wolffian ducts, abnormalities of the kidneys may be found in conjunction with uterine abnormalities.

\section{Diagnosis}

A pelvic examination will typically reveal a double vagina and a double cervix.

Investigations are usually prompted on the basis of such findings as well as when reproductive problems are encountered. Helpful techniques to investigate the uterine structure are.

- Transvaginal ultrasonography and sonohysterography

- Hysterosalpingography ${ }^{12}$

- MRI and hysteroscopy

- Laparoscopy/laparotomy.

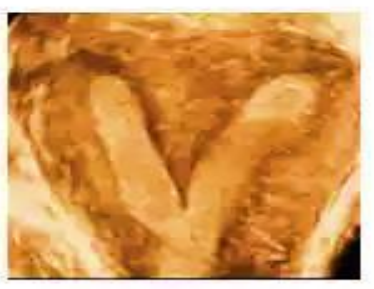

Septate uterus

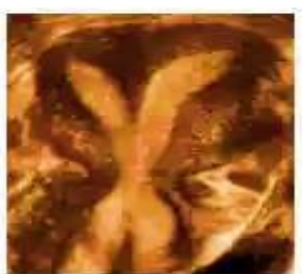

Double uterus

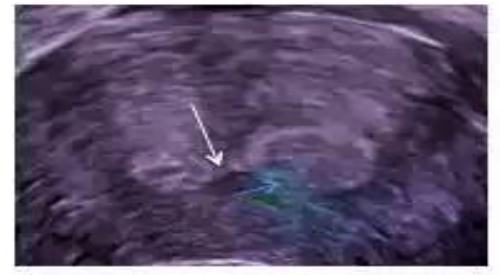

Intra-uterine adhesions (arrow)

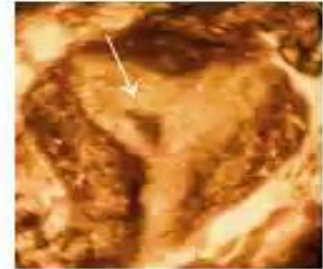

Intra-uterine adhesions on 3D scan (arrow)

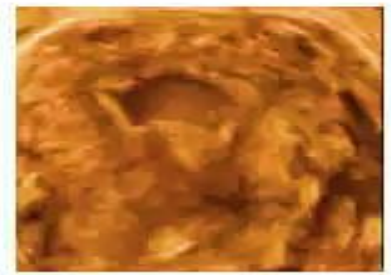

Severe intra-uterine adhesions blocking menstrual flow

Figure 5: 3D images of uterine anomalies. 
More recently 3-D ultrasonography has been advocated as an excellent non-invasive method to evaluate uterine malformations, it accurately analyses uterine structure, contour of fundus, muscular thickness and septum length. It is best performed during secretory phase of menstrual cycle.

\section{CONCLUSION}

The didelphys uterus is a very rare Mullerian duct anomaly with varying reproductive and gestational outcomes in comparison to other more common abnormalities. The ability to conceive remains a debatable issue as well. There is insufficient data on surgical correction (metroplasty); therefore it is not usually indicated; however excision of the vaginal septum may be required if the women is symptomatic. Didelphys uterus is not an indication for cesarean delivery unless the vaginal septum is thick and inelastic resulting in an increased risk for vaginal dystocia. Cervical incompetence has not been shown to occur in conjunction with the didelphys uterus. Lastly, when a didelphys uterus is diagnosed, renal anomalies should also be investigated to rule out Herlyn-WernerWunderlich (HWW) syndrome. Overall, the literature available on the didelphys uterus is quite limited at the present time. Therefore more studies are needed in order to better determine the reproductive and gestational outcomes, so that clinicians can adequately advise and care for their patients.

\section{Funding: No funding sources}

Conflict of interest: None declared

Ethical approval: Not required

\section{REFERENCES}

1. Heinonen PK. Uterus didelphys: a report of 26 cases. European Journal of Obstetrics and Gynecology and Reproductive Biology. 1984;17(5):345-50.

2. Heinonen PK. Clinical implications of the didelphic uterus: long-term follow-up of 49 cases. European
Journal of Obstetrics and Gynecology and Reproductive Biology. 2000;91(2):183-90.

3. Raga F, Bauset C, Remohi J, Bonilla-Musoles F, Simon C, Pellicer A. Reproductive impact of congenital Mullerian anomalies. Human Reproduction. 1997;12(10):2277-81.

4. Grimbizis GF, Camus M, Tarlatzis BC, Bontis JN, Devroey P. Clinical implications of uterine malformations and hysteroscopic treatment results. Human Reproduction Update. 2001;7(2):161-74.

5. Acen P. Reproductive performance of women with uterine malformations. Human Reproduction. 1993;8(1):122-6.

6. Humaira R, Sobia N, Nadia S, Asma TU. Frequency of mullerian duct abnormalities. J Rawal Med Coll. 2009;13(1):34-7.

7. Buttram VC, Gibbons WE. Mullerian anomalies: a proposed classification. (an analysis of 144 cases). Fertility and Sterility. 1979;32(1):40-6.

8. The American fertility society. The American fertility society classifications of adnexal adhesions, distal tubal occlusion, tubal occlusion secondary to tubal ligation, tubal pregnancies, mullerian anomalies and intrauterine adhesions. Fertility and Sterility. 1988;49(6):944-55.

9. Martınez-Beltran M, Gimenez J, Acien P. Uterus didelphys with septate cervix and unilateral endometrial carcinoma: a case report. Journal of Genital System and Disorders. 2012;1(1).

10. Rackow BW, Arici A. Reproductive performance of women with mullerian anomalies. Curr Opin Obstet Gynecol. 2007;19:229-37.

11. Chan YY, Jayaprakasan K, Tan A, Thornton JG, Coomarasamy A, Raine-Fenning NJ. Reproductive outcomes in women with congenital uterine anomalies: a systematic review. Ultrasound Obstet Gynecol. 2011;38(4):371-82.

12. Braun P, Grau FV, Pons RM, Enguix DP. Is hysterosalpingography able to diagnose all uterine malformations correctly? A retrospective study. Eur J Radiol. 2005;53:274-9.

Cite this article as: Rao SS, Anitha GS, Chandralekha P. Pregnancy in uterus didelphys delivered by caesarean delivery: case report. Int J Reprod Contracept Obstet Gynecol 2016;5:2434-7. 